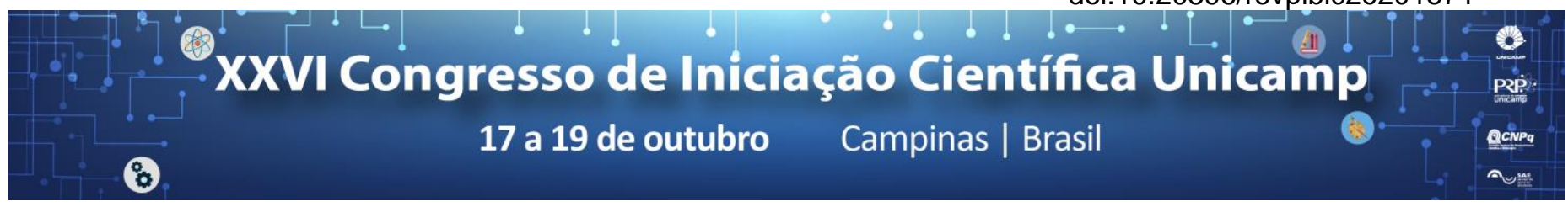

\title{
papel do gênero na percepção de segurança e na violência no contexto universitário
}

\section{Aletícia K. Martins}

\section{Resumo}

O presente projeto buscou determinar por meio de revisão bibliográfica quais são as perspectivas existentes na literatura acadêmica sobre o papel do gênero na vitimização, de forma a evidenciar não só as principais lacunas a serem preenchidas por esse tipo de pesquisa, mas também possíveis dificuldades na sua realização. Com isso, foi possível reunir o que já se sabe sobre o assunto, bem como indicar questões que ainda não foram aprofundadas sobre esse tema e que podem ser abordadas em pesquisas futuras.

\section{Palavras-chave: \\ Vitimização, Crime, Violência}

\section{Introdução}

A questão da violência tem sido um tema amplamente debatido por diversos setores da sociedade ao longo dos anos e sob diferentes perspectivas. Tem-se buscado compreender o porquê o fenômeno da violência ocorre e quais seriam as políticas públicas mais adequadas para prevenir e minimizar os danos decorrentes dela. Com isso, estudos nas áreas de sociologia, psicologia, antropologia e ciência política acerca das questões relacionadas a violência tem ganhado notoriedade ao longo dos últimos anos.

Neste sentido, uma contribuição valiosa para este debate é a que vem sendo desenvolvida no âmbito da economia do crime. Este tipo de abordagem, segundo Madallozo \& Furtado (2011) se iniciou a partir de Becker (1968), que buscou compreender o ato criminoso a partir da perspectiva da utilidade, conceito amplamente conhecido no contexto econômico. Desde então, ainda segundo Madallozo e Furtado, diversas pesquisas têm sido desenvolvidas nos Estados Unidos no sentido de se apurar os determinantes econômicos do crime, por meio de evidências econométricas, como é o caso de Ehrlich (1973), Mathieson e Passell (1976) e Cornwell e Trumbull (1994).

\section{Resultados e Discussão}

A partir do levantamento bibliográfico realizado, nota-se que uma parcela significativa das pesquisas de vitimização realizadas no Brasil tende a abordar o papel do gênero na vitimização. Porém, conforme apontado em Catão (2008), a falta de padronização e as diferenças metodológicas entre as pesquisas de vitimização limita a comparação dos dados obtidos.

Além disso, considerando que cada pesquisa abrange períodos de referência diferentes e são aplicadas em diferentes periodicidades, torna-se difícil estabelecer uma análise contínua e linear sobre o fenômeno da vitimização, de forma a identificar padrões e tendências ao longo do tempo.

Com relação a questão de gênero, nota-se a existência de pesquisas de vitimização especificamente voltadas para o tratamento da relação entre gênero e vitimização. Este é o caso da pesquisa "Visível e Invisível: A vitimização de Mulheres no Brasil" realizado pelo Fórum Brasileiro de Segurança Pública e o Instituto Datafolha em 2017. Graças a este trabalho foi possível elaborar um banco de dados que possibilitou análises sob diferentes perspectivas sobre a relação entre gênero e vitimização, bem como sobre a percepção da violência na visão das mulheres entrevistadas.

No entanto, percebe-se que a existência de estudos sobre a violência contra a mulher no contexto universitário ainda é pequena. Embora existam algumas pesquisas neste sentido, sua abrangência geográfica e temporal ainda se mostra bastante limitada.

\section{Conclusões}

Como já foi comentado, grande parte das pesquisas de vitimização aplicadas no Brasil ainda não possui padronização metodológica e na periodicidade de sua aplicação. No entanto, nota-se a relevância deste tipo de trabalho na tomada de decisões por parte de formuladores de políticas de segurança pública, principalmente no tocante a violência contra a mulher.

Sobretudo, nota-se que a relação entre a vitimização e gênero dentro das universidades ainda é pouco estudada do ponto de vista da economia do crime. Com isso, destaca-se a importância do fomento a este tipo de estudo não só em maior abrangência geográfica, mas também temporal, de forma a possibilitar análise aprofundada sobre essa questão.

\section{Agradecimentos}

A autora agradece ao CNPq pelo suporte financeiro e o Núcleo de Economia Social, Urbana e Regional (NESUR) por tornar essa pesquisa possível.

BECKER, G. S. Crime and punishment: an economic approach. The Journal of Political Economy 76 (2), 169-217, 1968

CATÃO, Y. Pesquisa de vitimização: notas metodológicas. Anuário do Fórum Brasileiro de Segurança Pública. São Paulo: FBSP, 2008

CORNWELL, C.; TRUMBULL, W. N. (1994) "Estimating the economic model of crime with panel data", The Review of Economics and Statistics, vol. 76: 360-366.

MADALOZZO, R. and G. M. FURTADO. Um estudo sobre vitimização para a cidade de São Paulo. Revista de Economia Política 31 (1), 160-180, 2011.

EHRLICH, Isaac. "Participation in illegitimate activities: A theoretical and empirical investigation", Journal of Political Economy, vol. 81: 521-565, 1973.

MATHIESON, D., PASSELL, P. Homicide and robbery in New York city: An economic model. Journal of Legal Studies, vol. 6: 83-98, 1976. 